\title{
Erratum to: Is Urinary Cadmium a Biomarker of Long-term Exposure in Humans? A Review
}

\author{
Caterina Vacchi-Suzzi $^{1}$ - Danielle Kruse ${ }^{2}$. James Harrington ${ }^{3}$. \\ Keith Levine $^{3}$ • Jaymie R. Meliker ${ }^{4}$
}

Published online: 26 October 2016

(C) Springer International Publishing AG 2016

Erratum to: Curr Envir Health Rpt (2016)

DOI 10.1007/s40572-016-0107-y

The original version of this article unfortunately contained a mistake. The presentation of Figure 1 was incorrect. The corrected Figure 1 is given below, along with the corresponding figure legend.

The original article was updated to reflect the correct Figure 1 as well.

The online version of the original article can be found at http://dx.doi. org/10.1007/s40572-016-0107-y.

\footnotetext{
Caterina Vacchi-Suzzi

caterina.vacchi-suzzi@stonybrookmedicine.edu

Danielle Kruse

danielle.kruse@stonybrookmedicine.edu

James Harrington

jharrington@rti.org

Keith Levine

levine@rti.org

Jaymie R. Meliker

jaymie.meliker@stonybrookmedicine.edu

1 Department of Family, Population and Preventive Medicine, Stony Brook University, Stony Brook, NY 11794, USA

2 Stony Brook University School of Medicine, Stony Brook, NY 11794, USA

3 Analytical Sciences Department, Innovation, Technology and Development RTI International, Research Triangle Park, NC 27709, USA

4 Program in Public Health, Department of Family, Population and Preventive Medicine Stony Brook University, Stony Brook, NY 11794, USA
} 




Fig. 1 Physiology of Cd excretion (Adapted from Nordberg [3] and Zalups [59], with permission from Elsevier) 